\title{
An Experimental Investigation Of Natural Convection With Solidification In A differentially Heated Cavity
}

\author{
M T Stickland*, T J Scanlon, J McKenzie \\ *Corresponding Author \\ Department of Mechanical Engineering, University of Strathclyde, Glasgow. G1 1XJ \\ Email: matt.stickland@strath.ac.uk
}

Tel: 01415482842

\begin{abstract}
This paper introduces an experimental rig used to produce data for the validation of computational models of natural convection within water in an enclosed cavity. The rig consisted of a rectangular cavity with the two long sides maintained at constant temperature. All other surfaces were insulated and adiabatic except for the top surface which was a free surface with an air gap between the free surface and the insulation. Experimental data in the form of velocity, ice growth rate and profiles are presented at 30 minute time steps with a cold wall temperature of $-10^{\circ} \mathrm{C}$ and hot wall temperature of $5^{\circ} \mathrm{C}$. The data produced has systematic and random errors of $\pm 0.4 \%$ and $\pm 0.5 \%$ respectively.
\end{abstract}




\section{Nomenclature}
A Aspect ratio $(=\mathrm{H} / \mathrm{L})$
$\mathrm{C}_{\mathrm{p}}$ specific heat at constant pressure, $\mathrm{J} / \mathrm{kgK}$
$\mathrm{H} \quad$ height of liquid, $\mathrm{m}$
$\mathrm{k}$ thermal conductivity $\mathrm{W} / \mathrm{mK}$
L length of cavity, $m$
Pr Prandtl number
$\mathrm{R}$ density distribution parameter
$\mathrm{Ra} \quad$ Rayleigh number
$\mathrm{T} \quad$ Temperature, $\mathrm{K}$
v vertical component of velocity, $\mathrm{m} / \mathrm{s}$

Greek symbols

$\alpha \quad$ thermal diffusivity, $\mathrm{m}^{2} / \mathrm{s}$

$\beta \quad$ thermal expansivity, /K

$\rho \quad$ density, $\mathrm{kg} / \mathrm{m}^{3}$

$\mu \quad$ dynamic viscosity, $\mathrm{Ns} / \mathrm{m}^{2}$

$v \quad$ kinematic viscosity, $\mathrm{m}^{2} / \mathrm{s}$

\section{Subscripts}

c cold

f fusion 
h hot

m maximum

r reference

i initial

\section{Introduction}

The analysis of buoyancy-driven flows with coupled solid-liquid phase change is important in a broad range of scientific and engineering fields. Examples of these may be found in the solidification and melting phenomena commonly encountered in metallurgical processes, latent heat thermal energy storage, oceanography, food processing and nuclear reactor safety; see Goldstein and Ramsey (1979), Ostrach (1983) and Feldman et al. (1989). Such a case involving heat transfer with phase change coupled with a moving solid-fluid boundary is often referred to as a Stefan problem.

In the published literature, a substantial body of numerical and experimental work has been dedicated to the solution of Stefan problems in the presence of buoyancy-driven natural convection. Extensive reviews of such investigations may be found in the publications of Viskanta, (1985), Yao and Prusa (1989) and Prescott and Incropera (1996). However, the majority of the experimental work is of a qualitative nature, Braga and Viskantha (1992), and there is a lack of suitable quantitative data that will allow the validation of computational fluid dynamics (CFD) codes which claim to be able to model the phase change phenomena. 
The authors have created a rig which will allow the measurement of temperature and velocity in a quasi two dimension cavity which has a heated wall opposite a cooled wall. All other surfaces are insulated and adiabatic apart from the free surface at the top of the cavity which had a $10 \mathrm{~mm}$ air gap between the free surface and the foam insulation. The free surface was unavoidable as the formation of ice causes the free surface to move upwards. The experimental data generated from the rig and presented in this paper has additional interest as the temperature range contained the temperature at which the density inversion phenomenon occurs within water. This phenomenon leads to some interesting buoyancy-driven flow patterns and ice structures. The simplicity of the rig allowed the boundary condition of a numerical model to be easily defined and the data produced is readily applicable to the validation of the numerical models.

The aim of this paper is to describe the experimental rig in detail and show a sample of the experimental data produced. The quality of the data is assessed through an error analysis.

\section{Experimental Rig}

The experimental rig used consisted of a cavity $75 \mathrm{~mm}$ wide, $150 \mathrm{~mm}$ high and $150 \mathrm{~mm}$ deep with an aspect ratio, A, of 2 . The vertical, opposite, sidewalls were integral heat exchangers. The end walls and bottom were created from $10 \mathrm{~mm}$ acrylic sheet to allow optical access. The top of the cavity was left open to create a free surface to allow for thermal expansion. The side wall heat exchangers were connected to two Grant Instruments (Cambridge) Ltd., R series, Low Temperature bath/circulators by insulated 
pipes through which circulated a mixture consisting of $50 \%$ glycol and $50 \%$ water. The constant temperature baths kept the coolant and side walls at a specified constant temperature within $\pm 0 \cdot 1^{\circ} \mathrm{C}$. Figure 1 shows a photograph of the experimental rig with the refrigeration units, flow cavity, and heat exchangers. For clarity the insulation material had been removed from the cavity. In operation the rig was encased in $50 \mathrm{~mm}$ of expanded polystyrene foam. The heat exchangers which make up the hot and cold walls of the cavity were made of brass and had nine ducts machined within them through which the water/glycol coolant passed, figure 2 . The inlet and outlet manifolds feeding these ducts had a variable diameter in order to ensure uniform flow rate through each duct. This ensured a uniform temperature and heat transfer rate on the surface of both heat exchangers. The design and heat transfer characteristics of the heat exchangers were modelled extensively using the Fluent CFD package in order to ensure the uniform temperature heat transfer rate.

Figure 3 shows a schematic of the rig and the optical path of the illumination laser. The Laser was a Lee Laser LDP-100MQG diode pumped Nd:YAG laser. The laser beam, with a wavelength of $532 \mathrm{~nm}$, had variable pulse frequencies between $5 \mathrm{kHz}$ and $50 \mathrm{kHz}$ with energy per pulse in the range of $1 \mathrm{~mJ}$ to $8 \mathrm{~mJ}$ per pulse. For this experiment the laser was run at $40 \mathrm{kHz}$ thereby producing a quasi continuous wave laser with a nominal power of approximately $40 \mathrm{~W}$. The beam was expanded into the cavity to form a two dimensional illumination sheet approximately $2 \mathrm{~mm}$ thick. For the majority of the experiment the laser shutter remained closed and was only opened for the time required to acquire the images of the flow field to avoid problems with the laser heating the 
working section. The camera used to acquire the images of the flow field was a Photron Ultracam high speed digital video system running at 60 frames per second with a resolution of 1024 x 1024 pixels. The camera head was fitted with a Nikon 60 mm lens and a $570 \mathrm{~nm}$ high pass filter

\subsection{Experimental procedure}

To ensure high repeatability of the experiments and to ensure that the initial boundary conditions of the experiment were well defined, in order to allow successful numerical modelling of the flow, the procedure at the start of the experiment was strictly adhered to. Before any fluid was introduced into the rig the refrigeration units were switched on and set to the hot and cold wall temperatures. The rig was then surrounded in insulation and allowed to reach equilibrium. When the rig was found to be in thermal equilibrium the seeding, 80-120 $\mu \mathrm{m}$ diameter fluorescent ballotini from John Hopkins University, was placed into the bottom of the test chamber and distilled water which had been cooled to the temperature of the cold wall siphoned into the rig to a depth of $140 \mathrm{~mm}$ to avoid the inclusion of air bubbles in the rig.. The top $10 \mathrm{~mm}$ of the rig was left empty to allow for the expansion of the water as the ice formed on the cold wall. The siphoning process took approximately 30 seconds and was sufficient to mix the seeding thoroughly into the water. The insulation on the upper surface was replaced when the water had been placed in the rig. When data were to be acquired the shutter on the laser was opened, the insulation on the viewing window was removed, the camera triggered and 512 images acquired. When the images had been acquired the shutter on the laser was closed, condensation that had formed on the viewing window was removed and the insulation 
was replaced. The total time elapsed for acquisition of the data from opening to closing the laser shutter was less than twenty seconds. Data were acquired at ten minute intervals. At the end of the experiment a laminated section of graph paper was placed in the plane of the laser sheet and photographed to create a datum from which the linear dimensions of the PIV analysis could be determined. Subsequent to the data acquisition the images were analysed by DANTEC FlowManager PIV software.

\subsection{Boundary Conditions}

This paper contains data for one set of boundary conditions which are shown in table 1;

The Rayleigh number was determined at $2.5^{\circ} \mathrm{C}$

$$
R a=\frac{g \beta\left(T_{h}-T_{f}\right) H^{3}}{v \alpha}
$$

Where $\mathrm{g}=9.81 \mathrm{~m} / \mathrm{s}^{2}, \mathrm{H}=0.14 \mathrm{~m}, \beta=5.037 \times 10^{-5} / \mathrm{K}, v=1.63 \times 10^{-6} \mathrm{~m}^{2} / \mathrm{s}$,

$\alpha=1.36 \times 10^{-7} \mathrm{~m}^{2} / \mathrm{s}, \mathrm{T}_{\mathrm{h}}=2.5^{\circ} \mathrm{C}, \mathrm{T}_{\mathrm{f}}=0.01^{\circ} \mathrm{C}$.

The Prandtl number

$$
\operatorname{Pr}=\frac{\mu C_{p}}{k}
$$

Where $\mathrm{Cp}=4.199 \mathrm{~kJ} / \mathrm{kgK}, \mathrm{k}=0.577 \mathrm{~W} / \mathrm{mK}, \mu=1.53 \times 10^{-3} \mathrm{~kg} / \mathrm{ms}$ and the density distribution parameter

$$
R=\left(T_{m}-T_{f}\right) /\left(T_{h}-T_{f}\right)
$$

were determined also.

\section{Results and Discussion}

This paper contains the results for one set of boundary conditions in order to demonstrate the capability of the experimental rig and the quality of the data produced. 


\subsection{PIV analysis}

The images analysed with DANTEC FlowManager software were 1024 x 1024 pixels analysed with an interrogation area of $32 \times 32$ pixels by cross correlation. Prior to analysis the images were masked so that the area outside of the experimental chamber produced nul vectors. A sample of the vector maps produced may be seen in figure 4 . It should be noted that all vector maps, including the one shown, had no post processing applied.

\subsubsection{Determination of Cross Correlation Time Step}

The PIV images were acquired by high speed digital camera at 60 frames per second with exposure times of $1 / 250^{\text {th }}$ of a second with 512 images stored at each datapoint. It was therefore possible to carry out multiple cross correlation analyses over different time steps at each data point. Figure 5 shows the effect of this time step on the vertical component of the velocity calculated at a point in the centre of the cavity within the high speed flow field and also the effect of time step on the standard deviation. It may be seen that the velocity calculated was dependent upon the time step used for the cross correlation. The standard deviation was also found to drop significantly as the time step was increased and the calculated velocity became constant. It was therefore decided to use a time step of 1.333 seconds which corresponded to cross correlating images separated by 80 frames. Thus, the data presented in this paper, had a standard deviation of approximately $0.002 \mathrm{~mm} / \mathrm{s}$ in the high speed flow within the body of the chamber and a standard error of $\pm 0.0008 \mathrm{~mm} / \mathrm{s}$ corresponding to a standard deviation of $0.8 \%$ and 
standard error of $\pm 0.4 \%$. Combined with this estimate of the random uncertainty in the data consideration must also be given to the systematic gain uncertainty included in the data due to the measurement of the scale used to obtain a linear dimension for the PIV analysis. It was estimated that this was of the order $\pm 0.5 \%$. The low standard deviation within the data was not unexpected as the work of Gebhart et al (1988) suggested that transition to turbulent convective flow within a cavity should not occur until a Rayleigh number of $10^{9}$

\subsubsection{Repeatability}

In order to assess the repeatability of the experiment it was repeated three times with the same initial boundary conditions. It may be seen from figure 6 that the repeatability was acceptable. The slight disparity between the shear layer velocity profiles on the right hand wall in one dataset was thought to be due to the analysis mesh not capturing the high velocity peak in this one case.

\subsection{Streamlines}

Figure 7 shows the streamlines within the flow field after 30,60 and 90 minutes. It may be seen that they highlight the effect of the density extremum on the flow field. Water has the unique property that the maximum density does not exist in the solid phase but occurs at approximately $4^{\circ} \mathrm{C}$. Thus, at the top of the left, hot, wall the water had a temperature below $4^{\circ} \mathrm{C}$. The hot wall heated the water, its density increased, and descended due to the negative buoyancy. As the water temperature rose and passed the temperature for maximum density the flow started to experience positive buoyancy, tried to rise and 
separated. The separation caused the recirculation zone in the lower left quadrant of the cavity which contained fluid above the extremum temperature. This recirculation zone exhibited the conventional buoyancy effect of rising next to the hot wall. The rising heated water met the descending cold water which again forced the separation from the hot wall. The fluid in the separated shear layer crossed the cavity and came into contact with the cold wall where it was cooled below the extremum temperature. The density was therefore reduced and the positive buoyancy caused the cooling water to rise along the cold surface. It may be seen from figure 7 that, as the transient progressed, the separation point on the hot wall moved progressively lower as the bulk temperature within the cavity decreased. Thus, the time and hence distance for the water to reach the extremum temperature as it descended the hot wall increased and the separation was delayed moving closer to the bottom of the cavity as the experiment progressed.

\subsection{Velocity profiles}

A plot of the vertical, $\mathrm{v}$, component of the velocity vector at three heights within the chamber after 30, 60 and 90 minutes may be seen in figures 8,9 and 10 respectively. It may be seen from figure 8 that, at 30 minutes, the separation point, shown by the zero velocity gradient, existed approximately $70 \mathrm{~mm}$ from the base of the cavity on the hot wall. Above this point the velocity was positive and below was negative. Figure 9 shows that, after 60 minutes, the velocity on the hot wall at $35 \mathrm{~mm}$ was reducing and the velocity at $70 \mathrm{~mm}$ was negative indicating that separation point had dropped below mid height. Figure 10 shows that, at 90 minutes, the separation point existed $35 \mathrm{~mm}$ above the bottom of the cavity. In figures 8,9 and 10 it can be seen, from the increasing region of 
zero flow toward the right of the cavity and the displacement of the high velocity peaks on the cold wall towards the centre of the chamber, that the thickness of the ice sheet on the cold wall increased with time.

\subsection{Ice thickness}

The growth of the ice sheet on the cold wall of the chamber was determined from the PIV images, a sample of such an image may be seen in figure 11. Both images were acquired after 60 minutes. However, the image on the left of figure 11 shows the image of the flow field acquired through a $570 \mathrm{~nm}$ high pass filter which removed the reflected laser light and allowed only the fluorescent light from the seeding particles to pass to the camera sensor. It may be seen in this image that the ice front shows up as a distinct thin line where the fluorescent light is reflected from the surface of the ice sheet. The figure on the right shows the same flow field with the filter removed and illustrates why the images viewed through the high pass filter were used. In this case it may be seen that the reflected laser light from the surfaces of the chamber and the ice sheet caused considerable glare which introduced significant noise into the data contained within the image. In order to determine quantitative data about the position of the front of the ice sheet the images were imported into AutoCAD and scaled from known dimensions on the images. A line was then fitted through the ice front and the location of the line and hence the ice front within the cavity was determined. Figure 12 shows the position of the ice front at ten minute intervals and also shows the ice thickness at three heights within the chamber during the experiment. It may be seen that the ice growth rate decreased with time as the layer of ice created an insulating surface over the cold heat exchanger. The ice 
thickness was not constant up the plate but increased in thickness with height. At the top of the ice sheet it may be seen that there was a slight reduction in the ice growth rate due to the presence of the free surface of the water and the small air gap between the free surface and the upper layer of insulating foam.

\section{Conclusion}

This paper has shown that an experimental facility has been created which allows the quantitative measurement of the flow field in a cavity driven by natural convection. Vector maps were produced and velocity profiles at three heights within the chamber presented. The formation of the ice sheet on the cold wall of the cavity was measured and ice front profiles and sheet thickness presented. The data produced allowed the flow field within the cavity to be discussed and this highlighted the effect the phenomenon of the density extremum within liquid water has on the convective flow patterns at this temperature. The rig produced high quality data which showed good repeatability and accuracy. The boundary conditions of the experiment were well defined such that the data produced are ideal for validation of numerical models of the so called Stefan problem.

\section{References}


Braga, S.L. and Viskanta, R. (1992) Effect of density extremum on the solidification of water on a vertical wall of a rectangular cavity, Experimental Thermal and Fluid Science, Vol. 5, pp. 703-713,

Gebhart, B., Jaluria, Y., Mahajan, R. L. and Sammakia, B. (1988) Buoyancy induced flows and transport, Hemisphere, New York.

Feldman, D., Shapiro, M.M., Banu, D. and Fuks, C.J. (1989) Fatty acids and their mixtures as phase-change material for thermal energy storage, Solar Energy Materials, Vol. 18, pp. 201-216.

Goldstein, R. J. and Ramsey, J. W. (1979) Heat transfer to a melting solid with application to thermal energy storage systems, in Studies in Heat Transfer, A Festschrift for E.R.G. Eckert, J.P. Hartnet et al., Eds.,pp. 199-208, McGraw-Hill, Washington D.C.

Ostrach, S. (1983) Fluid mechanics in crystal growth, ASME J. Fluids Engineering, Vol. 105, pp. 5-20.

Prescott, P.J. and Incropera, F.P. (1996) Convection heat and mass transfer in alloy solidification, in Advances in Heat Transfer, Academic Press, Vol. 28, pp. 231-338.

Viskanta, R. (1985) Natural convection in melting and solidification, in Natural Convection: Fundamentals and Applications, S. Kakac et al, Eds., Hemisphere, Washington D.C., pp. 845-877, 1985.

Yao, L.S. and Prusa, J. (1989) Melting and freezing, in Advances in Heat Transfer, Academic Press, Vol. 19, pp. 1-95, 1989.

\section{List of Figures}


Figure 1: Photograph of experimental rig

Figure 2: section through heat exchanger showing refrigerant ducts

Figure 3: Diagram of experimental rig showing optical path.

Figure 4: Typical vector map produced by the Flowmanager software

Figure 5: Effect of time step on calculated velocity

Figure 6: Repeatability plot

Figure 7: Streamline at, from left to right, 30, 60 and 90 minutes

Figure 8: Vertical component of velocity at 30 minutes

Figure 9: Vertical component of velocity at 60 minutes

Figure 10: Vertical component of velocity at 90 minutes

Figure 11: PIV images

Figure 12: Ice profiles and ice thickness

\section{List of Tables}

Table 1: Experimental Conditions 


\section{Figures}

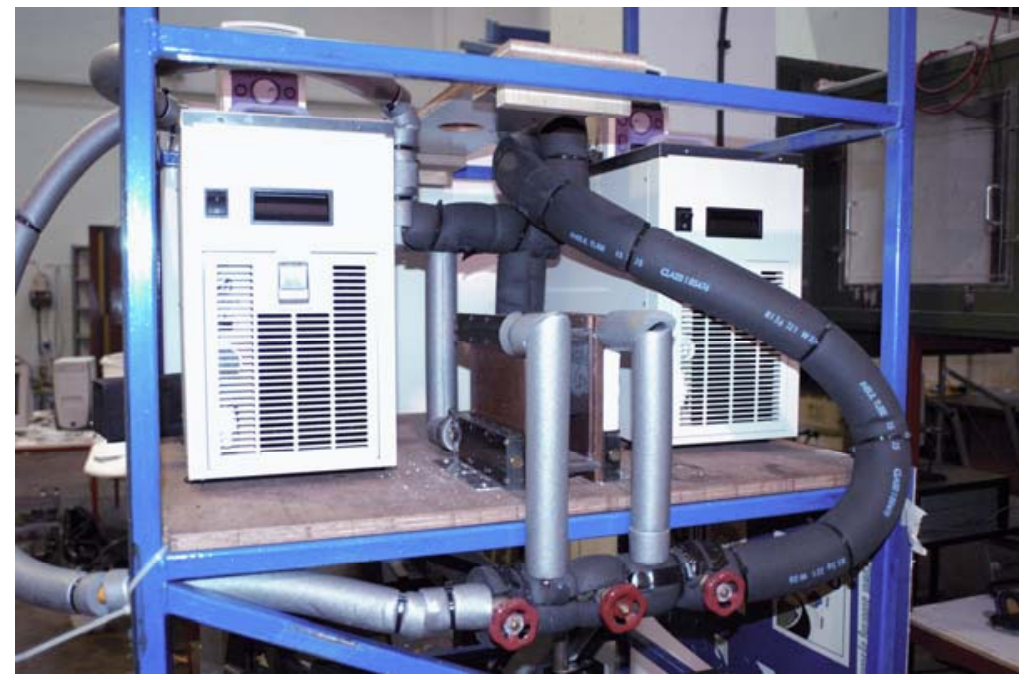

Figure 1: Photograph of experimental rig

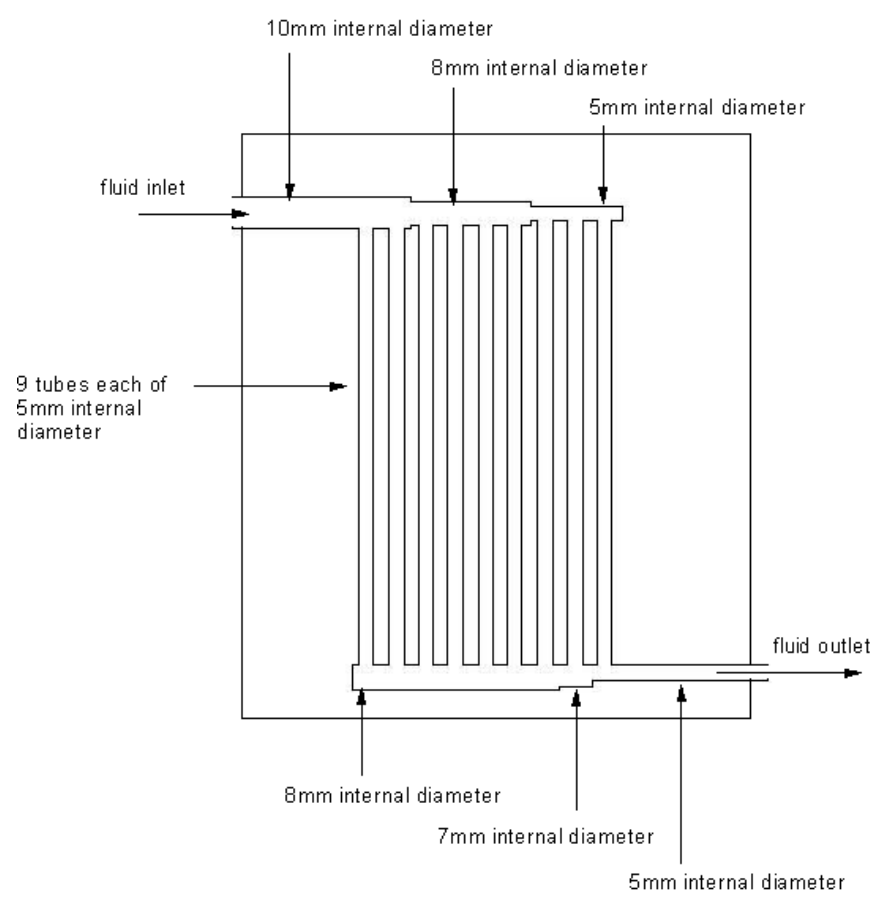

Figure 2: section through heat exchanger showing refrigerant ducts 


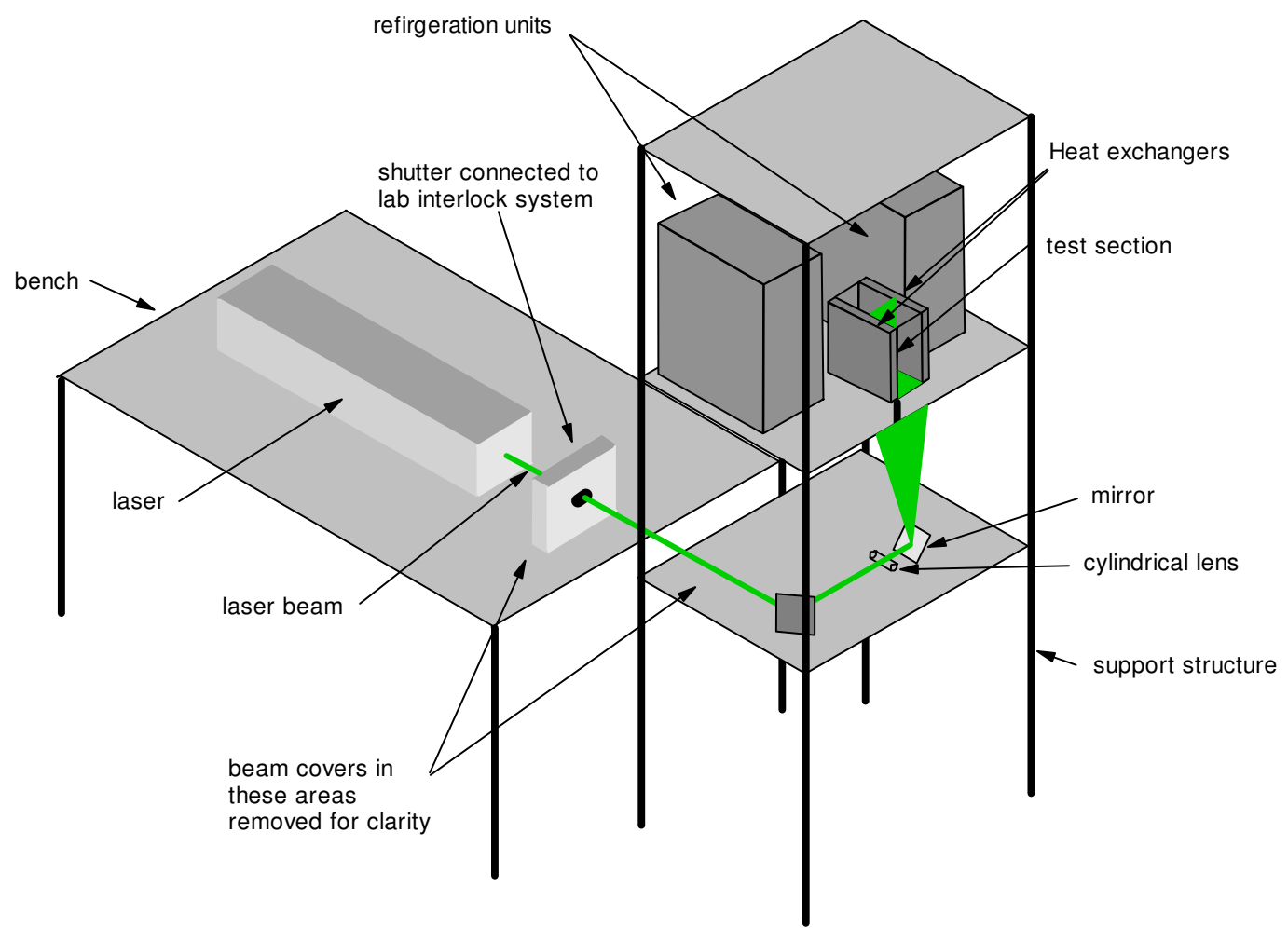

Figure 3: Diagram of experimental rig showing optical path.

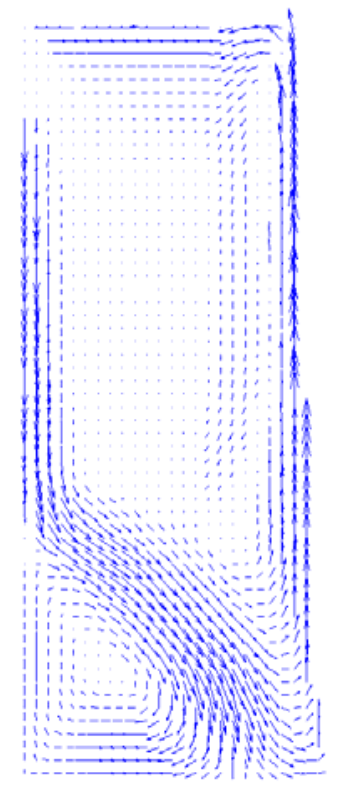

Figure 4: Typical vector map produced by the Flowmanager software 

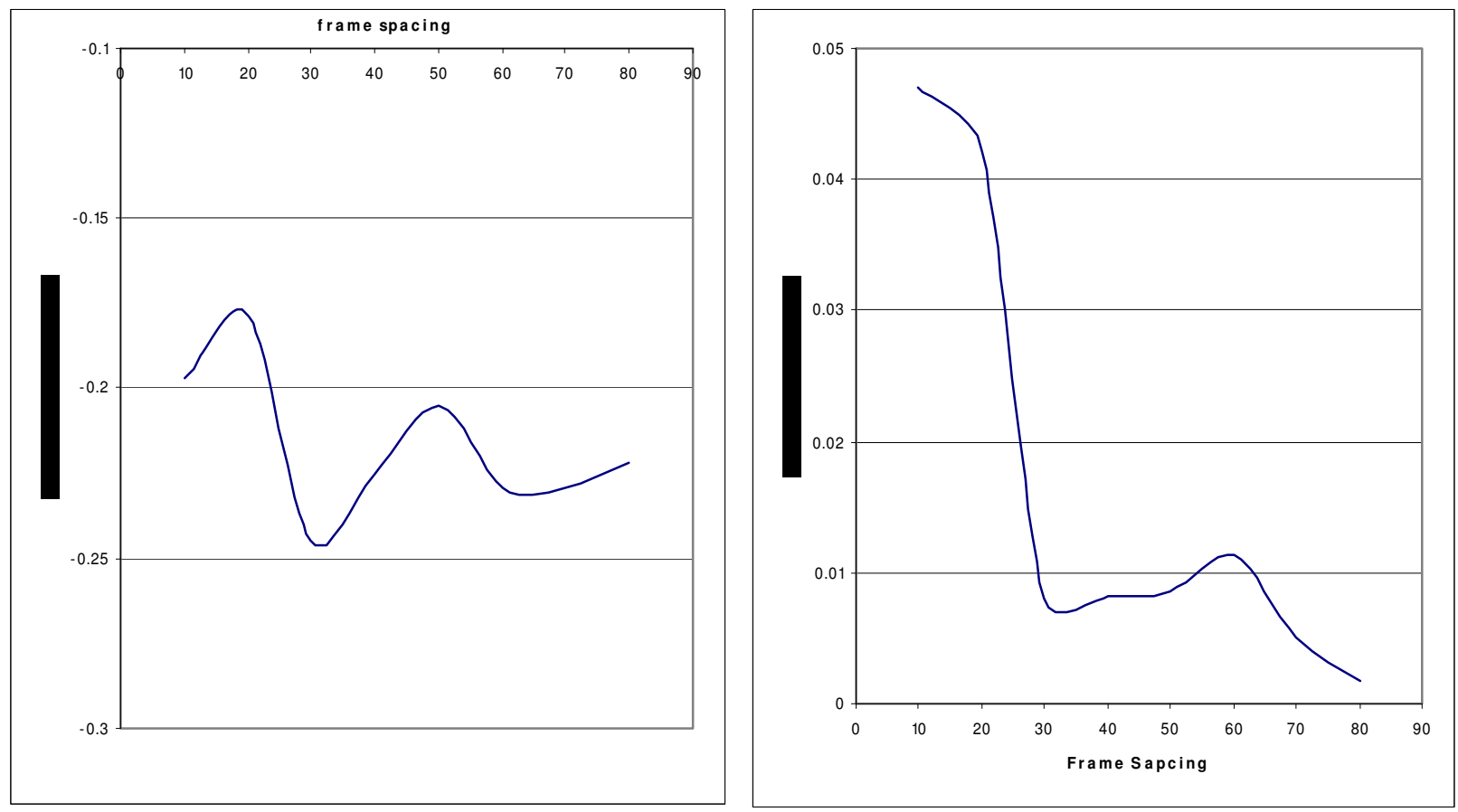

Figure 5: Effect of time step on calculated velocity

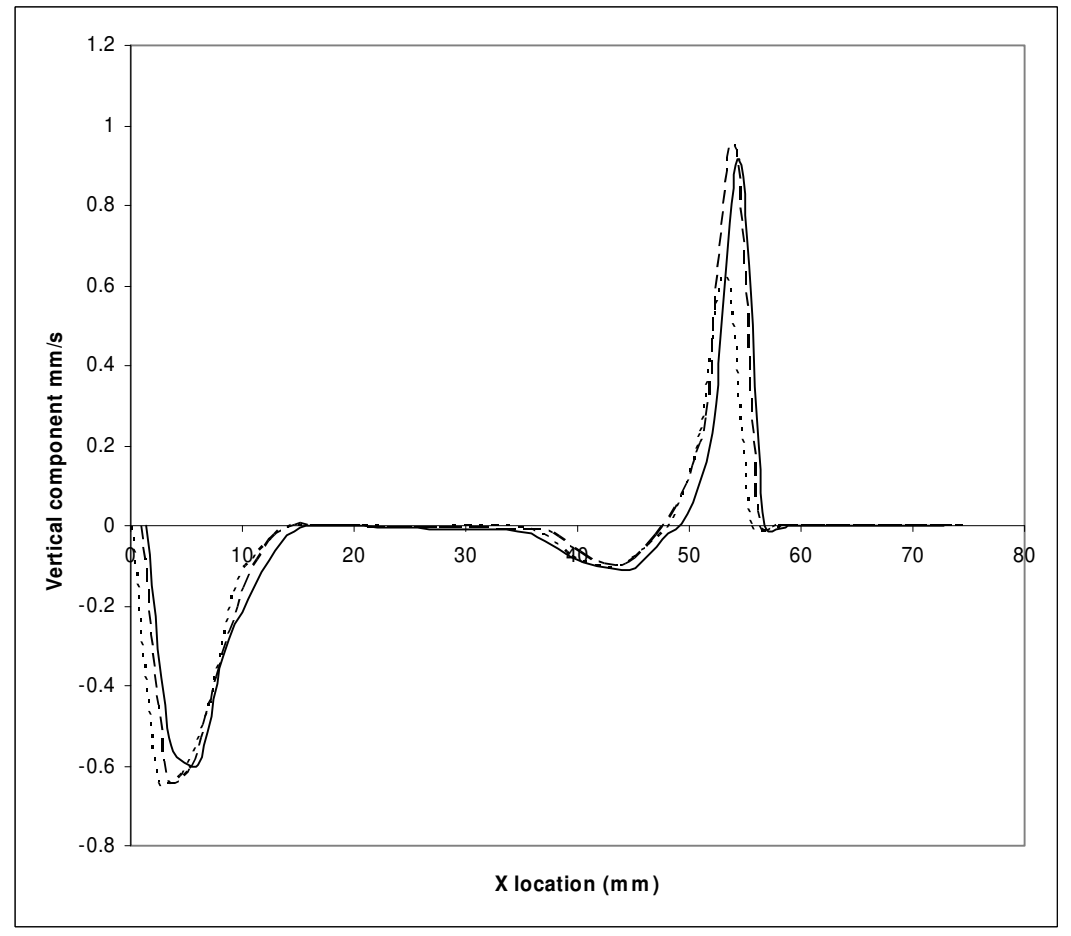

Figure 6: Repeatability plot 

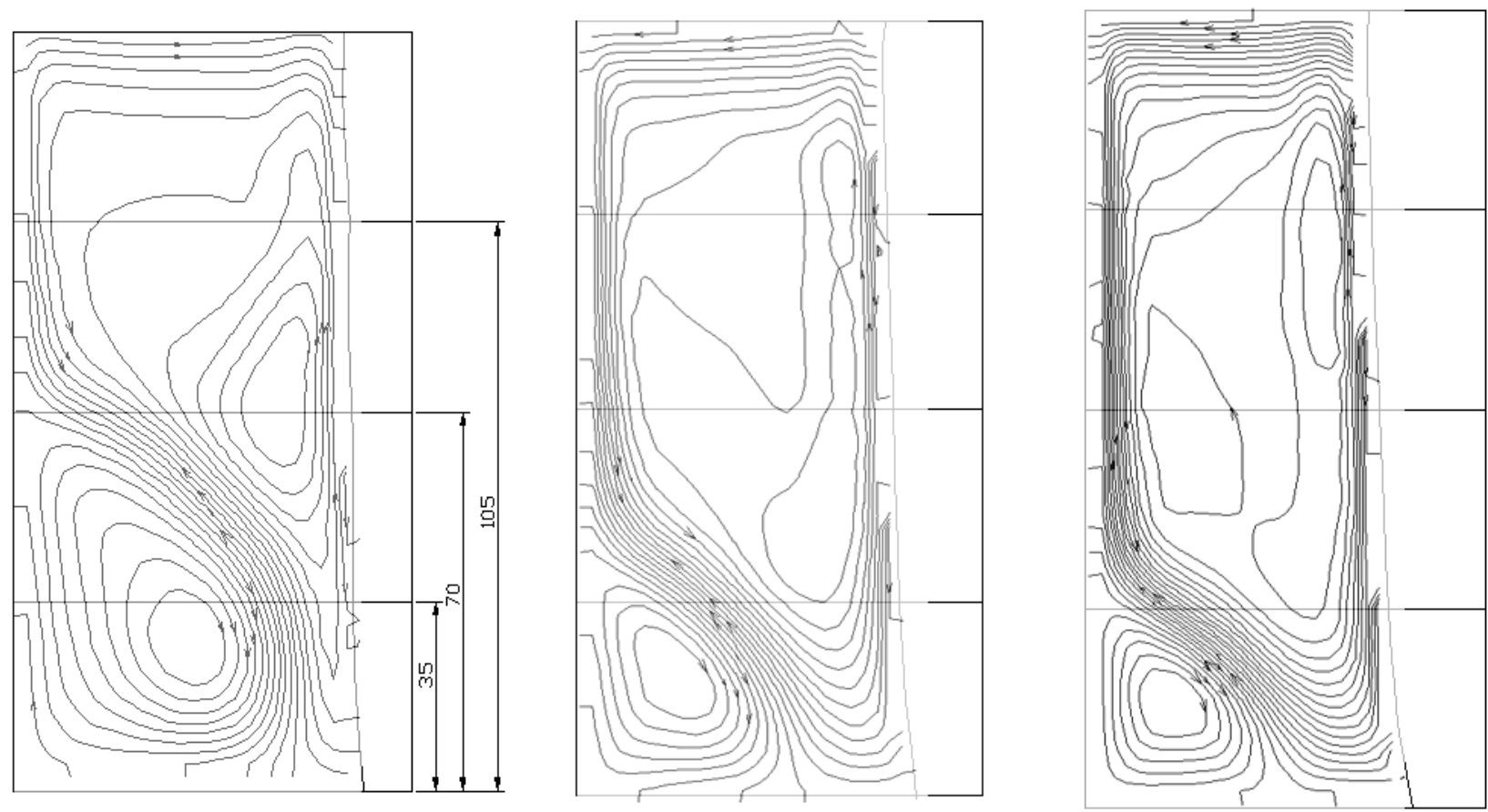

Figure 7: Streamline at, from left to right, 30, 60 and 90 minutes

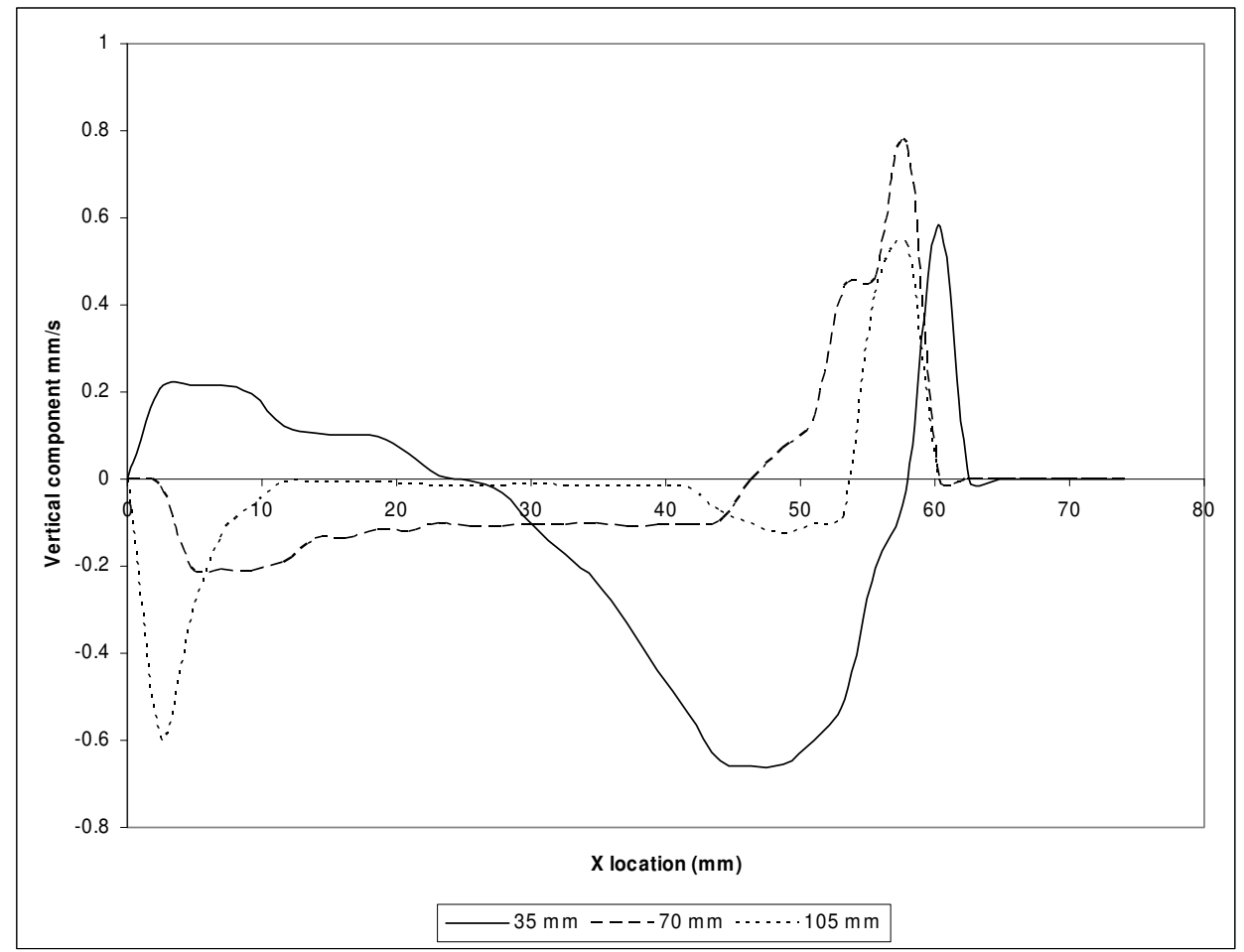

Figure 8: Vertical component of velocity at 30 minutes 


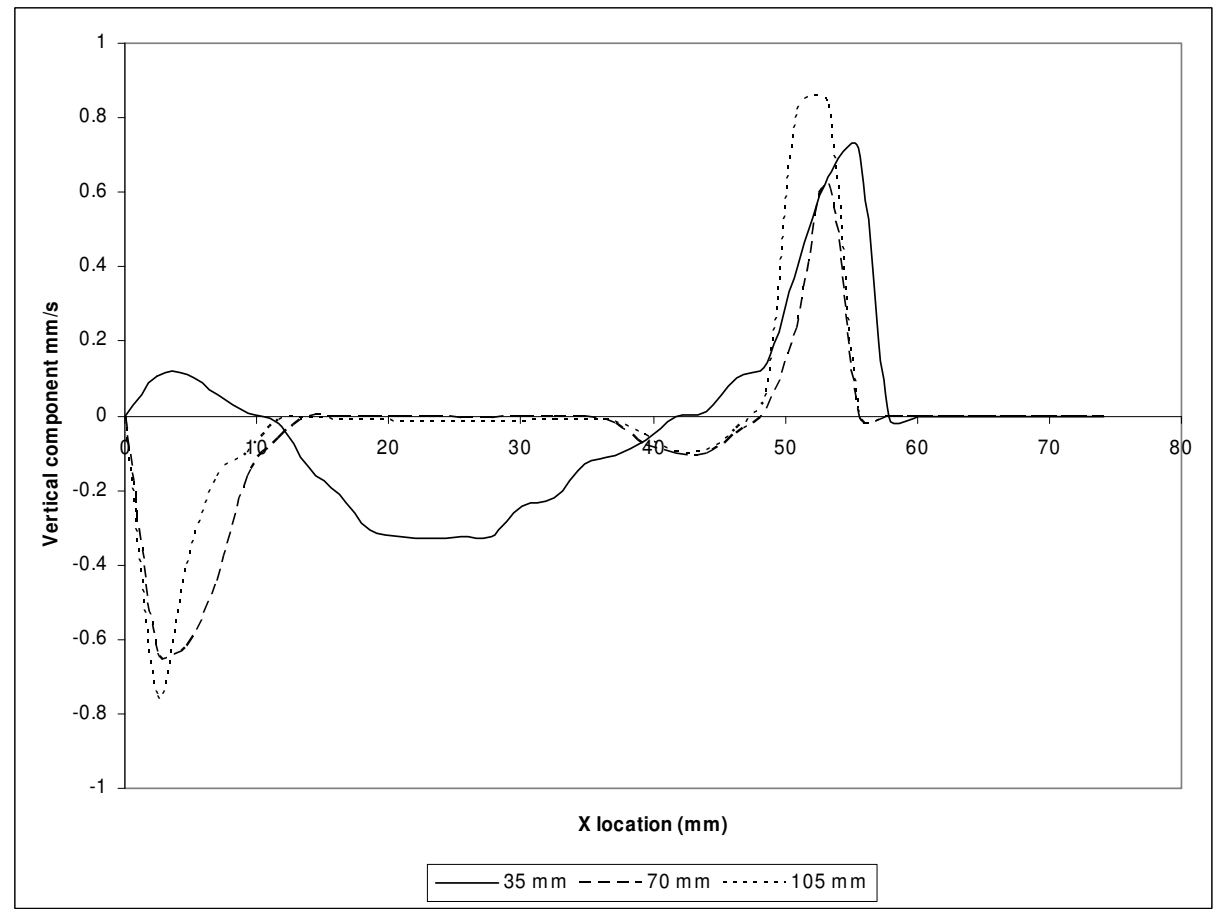

Figure 9: Vertical component of velocity at 60 minutes

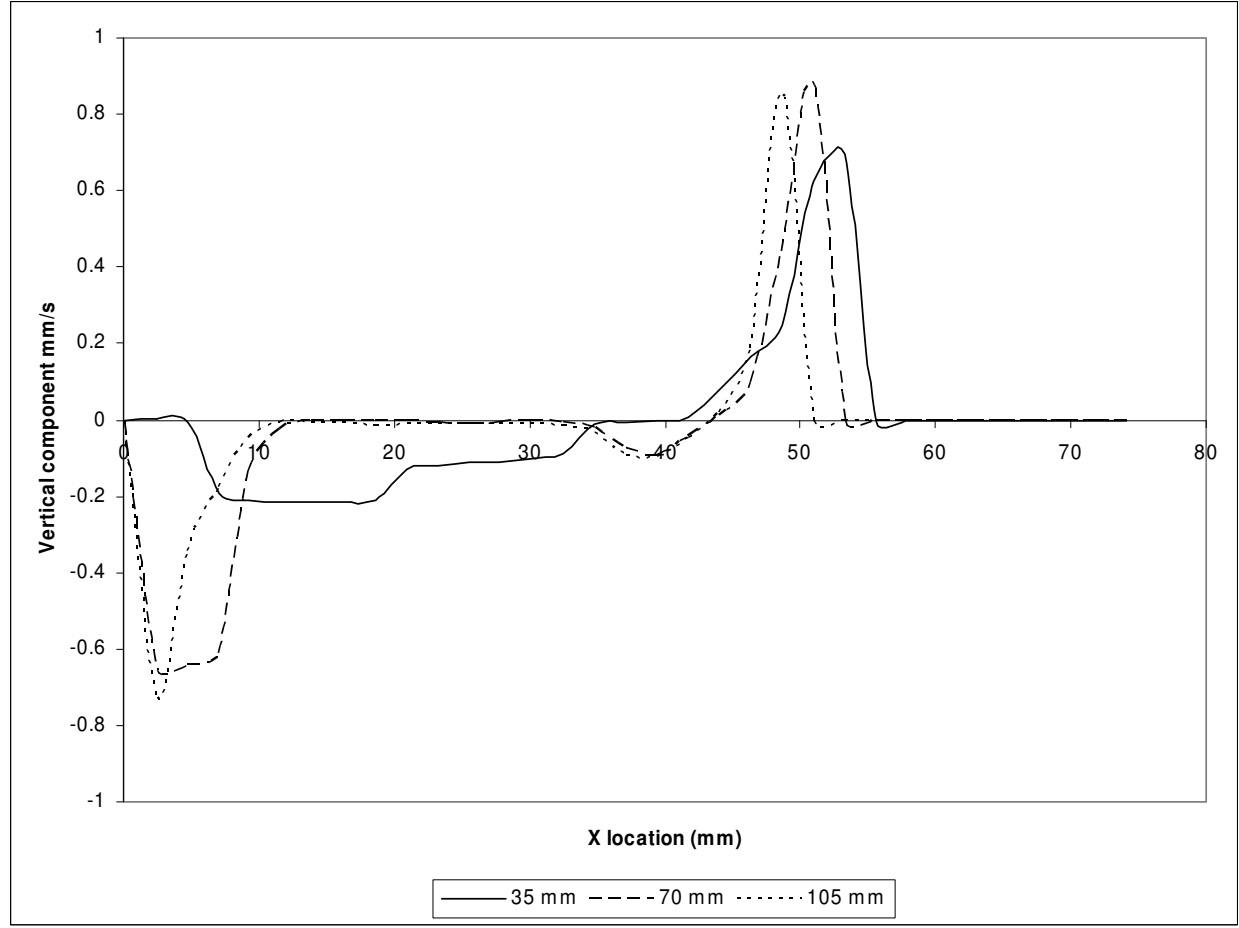

Figure 10: Vertical component of velocity at 90 minutes 

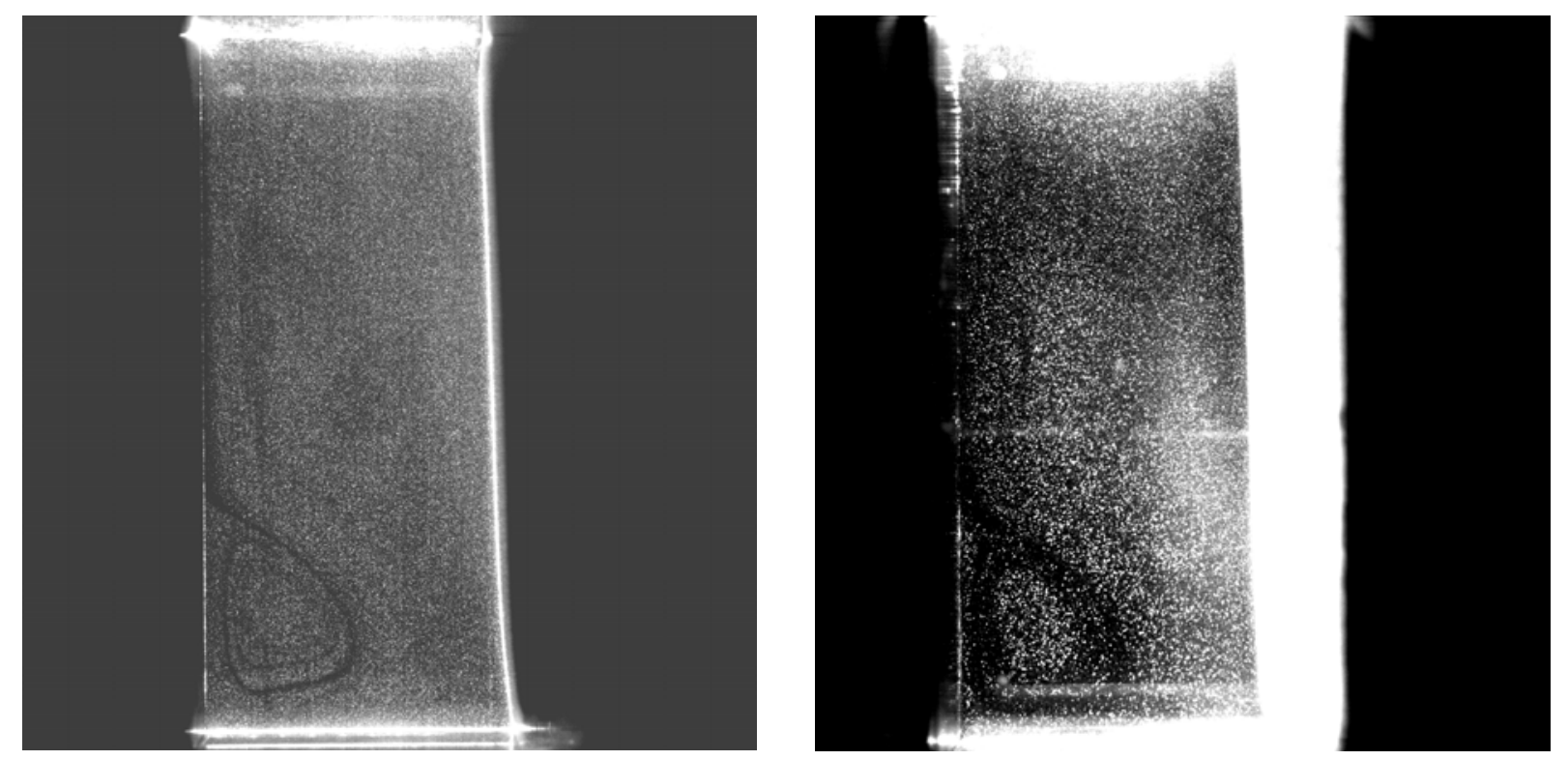

Figure 11: PIV images
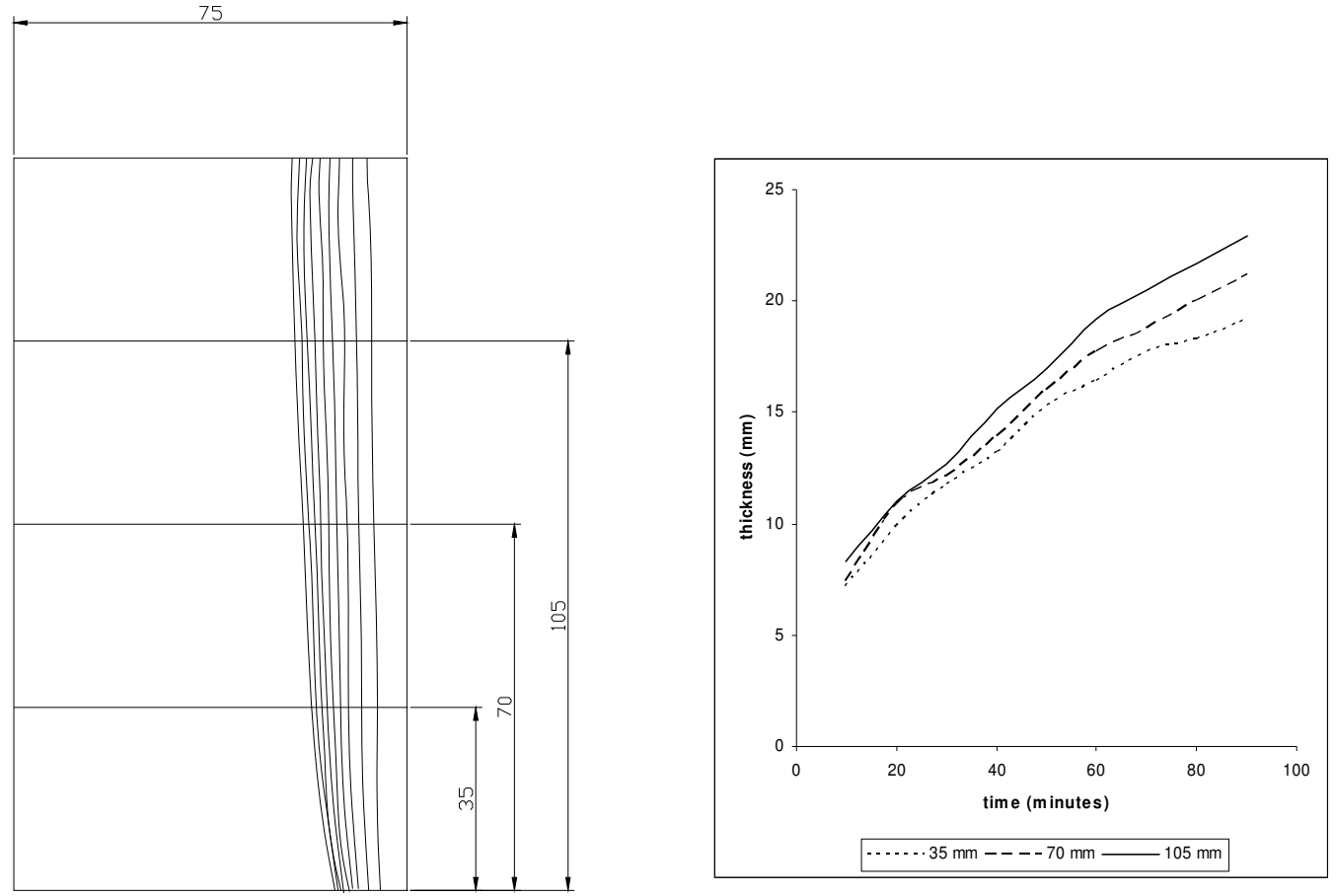

Figure 12: Ice profiles and ice thickness 


\begin{tabular}{|l|l|}
\hline Hot Wall temperature, $\mathrm{T}_{\mathrm{h}}$ & $5^{\circ} \mathrm{C}$ \\
\hline Cold Wall temperature $\mathrm{T}_{\mathrm{c}}$ & $-10^{\circ} \mathrm{C}$ \\
\hline Fluid & distilled water \\
\hline Initial water temperature, $\mathrm{T}_{\mathrm{i}}$ & $5^{\circ} \mathrm{C}$ \\
\hline Rayleigh Number, Ra & $3.057 \times 10^{7}$ \\
\hline Prandtl Number, Pr & 11.15 \\
\hline Density distribution parameter, $\mathrm{R}$ & 0.81 \\
\hline
\end{tabular}

Table 1; Experimental Conditions 